\title{
Noncirrhotic intrahepatic portal hypertension: Towards a unifying definition and etiology
}

\author{
B. S. Ramakrishna
}

Received: 24 May 2014 / Accepted: 24 May 2014 / Published online: 31 May 2014

(C) Indian Society of Gastroenterology 2014

Noncirrhotic portal fibrosis (NCPF) is a condition that was recognized in India in the middle of the last century principally by Basu, Das and Aikat in Kolkata [1-3]. Their investigations identified patients with portal hypertension who appeared to have portal fibrosis with intrahepatic portal hypertension and who did not meet the histopathological definition of cirrhosis. A large number of studies in the 1970s further described the clinical syndrome of NCPF outside of Bengal, particularly in northern India. Clinically, the disease was defined by repeated episodes of variceal bleeding that are well tolerated, moderate to large splenomegaly and absence of evidence of portal or splenic vein thrombosis. Although never documented by comparative studies, the impression of many academic gastroenterologists was that the disease was much more commonly diagnosed in the northern than in the southern part of India.

Similar syndromes were reported from elsewhere in the world, and a variety of names including idiopathic portal hypertension, incomplete septal cirrhosis, hepatoportal sclerosis, nodular regenerative hyperplasia, partial nodular transformation and idiopathic noncirrhotic portal hypertension were used to describe these [4-10]. All these entities were characterized by intrahepatic portal hypertension that was not due to cirrhosis (when the definition of cirrhosis is applied rigorously) and where liver function remains preserved until a late date. It seems likely that all such conditions represent a spectrum of the same disease that has more recently been termed noncirrhotic intrahepatic portal hypertension (NCIPH) [11, 12]. It has been reported that NCPF/NCIPH is on the decline in northern India [13]. However, it continues to be recognized in other parts of the country $[14,15]$. Indeed, the increasing

B. S. Ramakrishna $(\bowtie)$

S R M Institutes for Medical Science, 1, Jawaharlal Nehru Road,

Vadapalani, Chennai 600 026, India

e-mail:wurama@hotmail.com numbers of liver transplants performed in India has led to the rediscovery of NCIPH as a not insignificant cause of liver failure [16]. Thus, the disease may indeed progress to a stage requiring liver transplantation, although technically it would be difficult to label even the end-stage of the disease as cirrhosis $[17,18]$.

The pathological and hemodynamic findings in the liver in NCIPH including sclerosis and obliteration of the smaller portal vein radicles and periportal and perisinusoidal fibrosis have suggested the presence of a primarily vascular pathology involving the portal vein radicles. Several etiological agents have been identified as causes of a NCIPH-like syndrome in the past including arsenic toxicity and vinyl chloride [19-21]. As in many liver diseases that are centered on the portal vein, the possibility of gut-derived toxins acting on the vascular endothelium has been considered [22]. The initiating and perpetuating agents, and indeed the sequence of events leading to the end-stage morphology, remain to be described.

In this issue of the Journal, using two functional assays, Goel and colleagues reconfirm a deficient functional activity of the enzyme ADAMTS13 (A disintegrin and metalloprotease with thrombospondin type 1 motif, member 13) in Indian patients with NCIPH [23]. This enzyme cleaves von Willebrand factor, and the authors speculate that the absence of ADAMTS13 activity in NCIPH may lead to platelet microthrombi in the portal venous radicles leading eventually to obliteration of the small branches of the portal vein and portal hypertension. Earlier studies in the UK had indicated that the activity of this protein was reduced in the blood of patients with NCIPH and good liver function [11]. Cirrhosis is accompanied by defective synthesis of a number of proteins involved in the coagulation cascade. It has been shown in earlier studies that activity of this protein is reduced in advanced cirrhosis with decompensated liver function [24]. In the current study, median activity of ADAMTS13 was 30\% in Child A grade NCIPH patients compared to $100 \%$ in Child A 
cirrhotics. This suggests that the observed reduction in ADAMTS13 activity may indeed be a primary phenomenon in NCIPH. On the basis of circumstantial and indirect evidence, the authors argue plausibly that low ADAMTS13 activity or increased von Willebrand factor levels, or both, may lead to platelet microthrombi in the presinusoidal branches of the portal vein and thus on to NCIPH. ADAMTS13 is synthesized by the hepatic stellate cells (HSC) [25]. The role of HSC in NCIPH is not known, and other measures of HSC function have not been measured in NCIPH in this or in other studies. The possibility must, therefore, remain that the reduced ADAMTS13 activity noted in NCIPH patients is an epiphenomenon and that it merely reflects a defect of HSC with disease pathogenesis being mediated by other molecules that are affected in parallel with ADAMTS13 activity. It would be of interest to explore the possibility that there exists a primary abnormality of the HSC in NCIPH. The increasing availability of explant livers from patients with this condition may provide an opportunity in this era of molecular investigation.

\section{References}

1. Basu AK. Chronic Bengal splenomegaly and allied states of portal hypertension. Ann R Coll Surg Engl. 1959;24:137-58.

2. Mallik KC, Sen Gupta KP, Basu AK, Biswas SK, Pal NC, Boyer J. Non-cirrhotic portal fibrosis with portal hypertension: a new syndrome. II. Histopathological studies. Indian J Med Res. 1967;55: $351-9$.

3. Basu AK, Boyer J, Bhattacharya R, Mallik KC, Sen Gupta KP. Noncirrhotic portal fibrosis with portal hypertension: a new syndrome. I. Clinical and function studies and results of operations. Indian J Med Res. 1967;55:336-50.

4. Sciot R, Staessen D, Van Damme B, et al. Incomplete septal cirrhosis: Histopathological aspects. Histopathology. 1988;13:593-603.

5. Ludwig J, Hashimoto E, Obata H, Baldus WP. Idiopathic portal hypertension; a histopathological study of 26 Japanese cases. Histopathology. 1993;22:227-34.

6. Nakanuma Y, Hoso M, Sasaki M, et al. Histopathology of the liver in non-cirrhotic portal hypertension of unknown aetiology. Histopathology. 1996;28:195-204.

7. Hillaire S, Bonte E, Denninger MH, et al. Idiopathic non-cirrhotic intrahepatic portal hypertension in the West: a re-evaluation in 28 patients. Gut. 2002;51:275-80.

8. Dhiman RK, Chawla Y, Vasishta RK, et al. Non-cirrhotic portal fibrosis (idiopathic portal hypertension): Experience with 151 patients and a review of the literature. J Gastroenterol Hepatol. 2002;17:6-16.

9. Schinoni MI, Andrade Z, de Freitas LA, Oliveira R, Paraná R. Incomplete septal cirrhosis: an enigmatic disease. Liver Int. 2004;24:452-6.

10. Schouten JN, Garcia-Pagan JC, Valla DC, Janssen HL. Idiopathic noncirrhotic portal hypertension. Hepatology. 2011;54:1071-81.

11. Mackie I, Eapen CE, Neil D, et al. Idiopathic noncirrhotic intrahepatic portal hypertension is associated with sustained ADAMTS13 Deficiency. Dig Dis Sci. 2011;56:2456-65.

12. Eapen CE, Nightingale P, Hubscher SG, et al. Non-cirrhotic intrahepatic portal hypertension: associated gut diseases and prognostic factors. Dig Dis Sci. 2011;56:227-35.

13. Chawla Y, Duseja A. Non-cirrhotic portal fibrosis (NCPF) is a vanishing disease in India. Trop Gastroenterol. 2003;24:45-6.

14. Goel A, Ramakrishna B, Madhu K, et al. Idiopathic noncirrhotic intrahepatic portal hypertension is an ongoing problem in India. Hepatology. 2011;54:2274-5.

15. Goel A, Madhu K, Zachariah U, et al. A study of aetiology of portal hypertension in adults (including the elderly) at a tertiary centre in southern India. Indian J Med Res. 2013;137:922-7.

16. Nayak NC, Jain D, Saigal S, Soin AS. Non-cirrhotic portal fibrosis: one disease with many names? An analysis from morphological study of native explant livers with end stage chronic liver disease. J Clin Pathol. 2011;64:592-8.

17. Bernard PH, Le Bail B, Cransac M, et al. Progression from idiopathic portal hypertension to incomplete septal cirrhosis with liver failure requiring liver transplantation. J Hepatol. 1995;22:495-9.

18. Krasinskas AM, Eghtesad B, Kamath PS, Demetris AJ, Abraham SC. Liver transplantation for severe intrahepatic noncirrhotic portal hypertension. Liver Transpl. 2005;11:627-34.

19. Datta DV, Mitra SK, Chhuttani PN, Chakravarti RN. Chronic oral arsenic intoxication as a possible aetiological factor in idiopathic portal hypertension (non-cirrhotic portal fibrosis) in India. Gut. 1979;20:378-84.

20. Guha Mazumder DN. Chronic arsenic toxicity \& human health. Indian J Med Res. 2008;128:436-47.

21. Blendis LM, Smith PM, Lawrie BW, Stephens MR, Evans WD. Portal hypertension in vinyl chloride monomer workers. A hemodynamic study. Gastroenterology. 1978;75:206-11.

22. Egermayer P. Epidemics of vascular toxicity and pulmonary hypertension: What can be learned? J Intern Med. 2000;247:11-7.

23. Goel A, Alagammai PL, Nair SC, et al. ADAMTS13 deficiency, despite well compensated liver functions in patients with noncirrhotic portal hypertension. Indian J Gastroenterol. 2014;33: doi 10.1007/ s12664-014-0460-4.

24. Uemura M, Fujimura Y, Matsumoto M, et al. Comprehensive analysis of ADAMTS13 in patients with liver cirrhosis. Thromb Haemost. 2008;99:1019-29.

25. Uemura M, Tatsumi K, Matsumoto $M$, et al. Localization of ADAMTS13 to the stellate cells of human liver. Blood. 2005;106: $922-4$. 